\title{
Video-Assisted Thoracoscopy versus Thoracotomy for Primary Spontaneous Pneumothorax: A Randomized Controlled Trial
}

\author{
Adel K. Ayed ${ }^{a}$ Hassan Jamal Al-Din ${ }^{b}$ \\ aKuwait University, Faculty of Medicine, Department of Surgery, and \\ ${ }^{b}$ Chest Diseases Hospital, Ministry of Public Health, Kuwait
}

\section{Key Words}

Thoracoscopy. Spontaneous

pneumothorax $\cdot$ Thoracotomy

\begin{abstract}
Objective: Video-assisted thoracic surgery has been evaluated to replace thoracotomy for recurrent or persistent spontaneous pneumothorax. This study aimed to compare the clinical results and long-term follow-up of both procedures in treating primary spontaneous pneumothorax. Methods: In a prospective comparison, all 60 patients aged 1457 years with recurrent or persistent primary spontaneous pneumothorax seen at the Chest Diseases Hospital in Kuwait were randomly allocated to treatment by video-assisted surgery or thoracotomy. Subsequently various factors were analysed and compared in both groups, and the follow-up of both procedures was 3 years. Results: The mean
\end{abstract}

\begin{tabular}{ll}
\hline KARGER & ( ) 2000 S. Karger AG, Basel \\
Fax +41 61306 1234 $34-7571 / 00 / 0092-0113 \$ 17.50 / 0$ \\
$\begin{array}{l}\text { E-Mail karger@karger.ch } \\
\text { www.karger.com }\end{array}$ & $\begin{array}{l}\text { Accessible online at: } \\
\text { www.karger.com/journals/mpp }\end{array}$
\end{tabular}

and standard deviation (SD) operating time was longer in the thoracotomy group (95.3 \pm $16.4 \mathrm{~min})$ than in those undergoing videoassisted thoracoscopy $(77.5 \pm 13.7 \mathrm{~min} ; \mathrm{p}<$ $0.0001)$. The mean \pm SD amount of analgesics (Demerol) used in the first $12 \mathrm{~h}$ postoperatively was $67.16 \pm 27.1 \mathrm{mg}$ in the videoassisted thoracoscopy group and $148.3 \pm$ $24.5 \mathrm{mg}$ in the thoracotomy group $(p<$ 0.0001). The mean 24-hour chest tube drainage was less in the video-assisted thoracoscopy group than in the thoracotomy group ( 82 vs. $347.1 \mathrm{ml} ; \mathrm{p}<0.0001$ ). The mean duration of intercostal chest tube was 4.1 days in the thoracoscopy group and 5 days in the thoracotomy group ( $p=0.18$ ). The length of hospital stay was shorter in the thoracoscopy group than in the thoracotomy group (6.5 vs. 10.7 days; $p<0.0001$ ). After a follow-up of 3 years, the number of recurrences was 3 in the thoracoscopy group and none in the thoracotomy group. Conclusion: Video-assisted 
thoracoscopy has many clinical advantages over thoracotomy for recurrent or persistent primary spontaneous pneumothorax; but it results in a higher recurrence rate. The future role of video-assisted thoracoscopic surgery in this disease remains to be determined by a larger study.

$$
\text { Copyright @ } 2000 \text { S. Karger AG, Basel }
$$

\section{Introduction}

Spontaneous pneumothorax (SP) can be either primary SP due to the rupture of a subpleural bleb or secondary SP due to underlying lung disease, usually bullous emphysema. Surgical management of SP includes resection of blebs or blind apical stapling when no obvious lesion has been identified, and to create adhesions by performing pleurectomy or apleurodesis to prevent any further recurrence $[1,2]$. Standard surgical intervention has been by axillary or lateral thoracotomy [3]. To reduce thoracotomy-related morbidity, the use of video-assisted thoracoscopic surgery (VATS) has been evaluated to replace thoracotomy in the treatment of recurrent SP [4-7]. The long-term results of the VATS procedure are not well-known in many studies and previous controlled studies show no obvious advantage of VATS when compared with a limited thoracotomy [8, 9]. Therefore, we performed a prospective randomized trial in Kuwait to compare thoracotomy and VATS in the treatment of recurrent or persistent primary SP with a follow-up of 3 years.

\section{Patients and Methods}

The common practice at our department is to treat patients with first time or recurrent SP by observation or insertion of a chest tube. Chest tube was not inserted if the size of the pneumothorax was less than $25 \%$ of the volume of the hemithorax and the patient had no dyspnoea. Chest tube was inserted if the size of the pneumothorax exceeded $25 \%$ of the volume of the hemithorax at presentation or the size progressed during observation. The chest tube was removed when the lung had been completely re-expanded and air leakage had ceased. Surgical treatment was performed if there was recurrent pneumothorax after the first episode or persistent SP in which there was an air leak persisting for more than 7 days.

From January 1993 to June 1995, all 60 patients requiring blebectomy by VATS or thoracotomy due to recurrent or persistent primary SP were included in this study at the Chest Diseases Hospital in Kuwait. Preoperative investigation included a chest radiograph and routine blood tests including complete blood count and serum electrolytes. The diagnosis of primary SP was based on the history and chest X-ray alone. Patients with underlying lung disease like emphysema and sarcoidosis were not included in the study.

Patients were randomly selected for an operation through either VATS or a thoracotomy. After careful explanation of both procedures and pointing out the differences between them, the patients selected an opaque envelope containing the mode of treatment. Informed consent was then received from each patient. None refused to participate in the trial. There were no exclusive criteria.

\section{Operative Technique of VATS}

With the patient under general anesthesia using a single-lumen endotracheal tube the patient was ventilated with reduced tidal volume throughout the procedure. The patient was placed in a posterolateral thoracotomy position. A $10-\mathrm{mm}$ trocar was introduced through a $1.5-\mathrm{cm}$ skin incision in the eighth intercostal space at the midaxillary line for the insertion of a 0-degree videothoracoscope (Karl Storz, Germany). Two additional ports were then inserted under direct vision: a $12-\mathrm{mm}$ trocar through the fifth intercostal space on the axillary line and a $12-\mathrm{mm}$ posterior trocar through the fifth intercostal space near the tip of the scapula. Bullae or blebs were identified and grasped with an empty sponge stick. When no blebs were visible, a small portion of the apical upper lobe was resected. The excision was done by using the endo-GIA stapling device (Autosuture Company, USA). Then apical parietal pleurectomy was performed in all cases. A $28 \mathrm{~F}$ chest tube was inserted through the inferior incision in the eighth intercostal space and connected to an underwater seal suction with a negative pressure of $20 \mathrm{~cm} \mathrm{H}_{2} \mathrm{O}$. No patient required a conversion to thoracotomy. 
Table 1. Summary of all cases of primary SP

\begin{tabular}{|c|c|c|c|c|c|c|c|}
\hline \multirow[t]{2}{*}{ Variable } & \multicolumn{3}{|c|}{ Thoracoscopy } & \multicolumn{3}{|c|}{ Thoracotomy } & \multirow[t]{2}{*}{$\mathrm{p}$ value } \\
\hline & mean & SD & $95 \% \mathrm{CI}$ & mean & SD & $95 \% \mathrm{CI}$ & \\
\hline Age, years & 25.9 & 6.3 & $23.5, \quad 28.19$ & 27.03 & 10.95 & 24.7 & 0.6 \\
\hline Operative time, $\min$ & 77.5 & 13.75 & $72.38,82.6$ & 95.3 & 16.4 & $89.2, \quad 101.4$ & $<0.0001$ \\
\hline Analgesia received, mg & 67.16 & 27.15 & $57.1, \quad 77.27$ & 148.3 & 24.5 & $139.2, \quad 157.4$ & $<0.0001$ \\
\hline 24-hour pleural drainage, $\mathrm{ml}$ & 82 & 15.4 & $76.26,87.7$ & 347.16 & 202.4 & $271.77,422.55$ & $<0.0001$ \\
\hline Chest tube, days & 4.16 & 2.46 & $3.25, \quad 5.1$ & 5.03 & 2.48 & $4.1, \quad 5.96$ & 0.18 \\
\hline Hospital stav, davs & 6.5 & 3.2 & $5.3, \quad 7.69$ & 10.73 & 4.1 & 12.26 & $<0.0001$ \\
\hline
\end{tabular}

$\mathrm{SD}=$ Standard deviation $; \mathrm{CI}=$ confidence interval.

Operative Procedures of Thoracotomy

With the patient under general anaesthesia, and using the single-lumen endotracheal tube, a limited posterolateral thoracotomy was made through the fifth intercostal space without muscle sparing. The ribs were spread gradually. The bullae were grasped with a Babcock forceps and divided; when no bullae or blebs were visible, a small portion of the apical upper tube was resected. The excision was done using GIA stapling device (Autosuture Company). Then, apical parietal pleurectomy was performed. A $28 \mathrm{~F}$ chest tube was inserted through another stab wound at the seventh intercostal space and placed on suction. The incision was closed in layers using absorbable sutures.

\section{Postoperative Care}

All patients were extubated in the operating room and transferred to the thoracic surgical ward. Antibiotic in the form of cefoxitin was given to all patients. Analgesics in the form of pethidine (Demerol) were administered intramuscularly every $4-6 \mathrm{~h}$ according to the patients' request, and oral analgesics (acetominophen) were given as needed.

The intercostal drains were removed when the underlying lung was fully expanded with no air leakage and less than $100 \mathrm{ml}$ of drainage through the tube for $24 \mathrm{~h}$. All patients were discharged from the hospital when fully mobile and when their pain was controlled by oral analgesia.

\section{Postoperative Assessment}

The following data were recorded: (1) operative time; (2) amount of analgesia in the first $12 \mathrm{~h}$; (3) total amount of intercostal drainage in the first $24 \mathrm{~h}$; (4) duration of chest tube; (5) duration of hospital stay; (6) rate

Surgical Treatment of Primary

Spontaneous Pneumothorax of recurrence. The follow-up chest radiograph was done at intervals of 1 week, 1 month, 1 year, 2 years and 3 years postoperatively. The recurrence was proved by chest radiography during the follow-up period.

\section{Statistical Analysis}

The unpaired Student's t test was used to assess the significance between means of the variables between the two methods (Statview 4.02 statistics package using Macintosh Centris 60 computer). Data are expressed as the mean \pm standard deviation. The level for significance was taken as $\mathrm{p} \leq 0.05$. The sample size (30 in each group) is believed to guarantee a precision in detecting significance between the two groups at type I error 0.05 and power $80 \%$.

\section{Results}

All data are summarized in table 1. Fiftyseven patients were males and 3 were females. Thirty patients were treated by VATS and 30 by limited posterolateral thoracotomy. On comparing the two groups, their ages were similar. The operative time was significantly longer in the thoracotomy group. The amount of analgesia and the 24-hour blood loss were greater in the thoracotomy group. There was no significant difference in the duration of chest tube in both groups. The mean length of hospital stay for VATS and thoracotomy was 
6.5 and 10.7 days, respectively $(\mathrm{p}<0.0001)$. There were no postoperative complications. There were no deaths during the follow-up period. During subsequent follow-up, recurrent pneumothorax developed in 3 patients in the VATS group and none after thoracotomy. Two cases that recurred 2 weeks later were treated conservatively. One case that recurred at 2 months was treated by a limited posterolateral thoracotomy. This case of recurrence showed no blebs or bullae during surgery. To date there have been no further recurrences of pneumothorax at 3 years follow-up postoperatively.

\section{Discussion}

The technique of VATS in the treatment of SP can be performed without single lung ventilation. Low tidal-volume ventilation was employed in all cases of this series while dissection or manipulation was performed. This degree of ventilation facilitates the identification and excision of the blebs.

We obtained good early results of VATS over the thoracotomy group. In this study video-assisted thoracoscopic treatment of primary SP needed less operating time than thoracotomy open procedure. This finding is not consistent with literature reports $[8,9]$ presumably due to the time being consumed in the opening and closing the incision in both approaches. In the thoracotomy, however, data in the literature reported less operative time with thoracotomy approach, while in our study, we used limited posterolateral thoracotomy incision without muscle sparing. The use of analgesics, the postoperative chest tube drainage and the postoperative hospital stay were reduced in the VATS group, confirming the results of previous reports $[4,6,10]$. The use of small incisions in the VATS group has demonstrated a trend towards less postopera- tive analgesic requirement. Thus, these patients were mobilized faster and had a shorter hospital stay $[9,11]$. The length of hospital stay in our study probably was determined by the postoperative incisional pain and the need for pain medication.

There were 3 recurrences in the VATS group and no recurrence in the thoracotomy group. The 3 recurrences occurred within 3 months of operation and in patients in whom no blebs had been identified. Apical stapling was done with apical pleurectomy. One patient required reoperation and the other 2 had a partial collapse and healed by rest without drainage. Most series report a recurrence rate after VATS procedures between 5 and $10 \%$ $[4,6,10,12,13]$. One reason for recurrence is failure to recognize the site of the leak in the absence of blebs, or unrecognized blebs or bullae. Another is inadequate pleurodesis, especially in between the trocar sites. In the study of Naunheim et al. [10], two factors predicted recurrence. When no bleb was seen, the recurrence rate was $27.3 \%$ versus 0 and $2.7 \%$ when one or multiple blebs, respectively, were identified. Apical excision reduced the recurrence rate to $1.8 \%$ compared with $23 \%$ when no excision was done. Mouroux et al. [12] had an overall recurrence rate of 3\%: 20\% in patients without stapling of the apex versus $1.5 \%$ in patients in whom this was done. Other studies have shown that VATS has less favourable long-term results than thoracotomy. In a prospective study Inderbitzi et al. [13] found that recurrence rate in 163 patients was $8.3 \%$ after VATS. Similarly, Bertrand et al. [4] had 4\% recurrence rate after VATS procedure.

Nevertheless, thoracotomy has some advantages compared with VATS. The blebs or bullae are easily visualized and the site of air leak is easier to identify. A formal pleurectomy or extensive pleurodesis is feasible in all places within the pleural cavity. Thus, the 
Table 2. Results of studies comparing VATS with thoracotomy in the treatment of spontaneous pneumothorax

\begin{tabular}{|c|c|c|c|c|c|c|c|c|}
\hline \multirow[t]{2}{*}{ Authors } & \multicolumn{2}{|c|}{$\begin{array}{l}\text { Operative time } \\
\mathrm{min}\end{array}$} & \multicolumn{2}{|c|}{$\begin{array}{l}\text { Chest tube duration } \\
\text { days }\end{array}$} & \multicolumn{2}{|c|}{$\begin{array}{l}\text { Hospital stay } \\
\text { days }\end{array}$} & \multicolumn{2}{|c|}{$\begin{array}{l}\text { Recurrence } \\
\%\end{array}$} \\
\hline & VATS & thoracotomy & VATS & thoracotomy & VATS & thoracotomy & VATS & thoracotomy \\
\hline Hazelrigg et al. [11] & - & - & 2 & 2.3 & 2.9 & 4.5 & 0 & 0 \\
\hline Waller et al. [9] & 45 & 37.5 & 2 & 2 & 4 & 5 & 6.6 & 3.3 \\
\hline Kim et al. [8] & 91.2 & 86.3 & 5 & 4.3 & - & - & 11 & 0 \\
\hline Bertrand et al. [4] & - & - & 4.4 & 5.6 & 6.9 & 10.3 & 3.6 & 1.1 \\
\hline Passlick et al. [7] & - & - & 4 & 5 & 8 & 11 & - & - \\
\hline Present study & 77.5 & 95 & 4 & 5 & 6.5 & 10.7 & 10 & 0 \\
\hline
\end{tabular}

chances of recurrence in a thoracotomy group are much less. Published data [1,3] concerning treatment of recurrent SP by thoracotomy showed a recurrence rate of less than $1 \%$, while Kim et al. [8] have shown no advantages of VATS over transaxillary mini thoracotomy. Other studies expressed their doubts about the advantage of VATS over thoracotomy $[7,8,14,15]$. Some studies comparing VATS and thoracotomy are summarized in table 2 .

In conclusion, the finding of this study confirms the advantages of VATS bullectomy and apical pleurectomy in the treatment of recurrent or persistent primary SP. The advantages are reduced operative time, less analgesic requirement and therefore faster mobilization and a shorter hospital stay. However, recurrence rate after VATS group is high and this should be taken into consideration. Therefore, the usefulness of VATS in patients with primary SP remains to be defined by a large prospective evaluation. Another important factor is to find a better way of pleural adhesiveness to prevent recurrence after VATS procedure.

\section{Acknowledgement}

We are thankful to Prof. M.A.A. Moussa for his help in the statistical analysis of these data and to Mrs. Monica D'Silva for her secretarial assistance.

\section{References}

1 Parry GW, Juniper ME, Dussek JE: Surgical intervention in spontaneous pneumothorax. Respir Med 1992;86:1-2.

2 Massard G, Thomas P, Wihlm JM: Minimally invasive management for first and recurrent pneumothorax. Ann Thorac Surg 1998;66:592599.
3 Murray KD, Matheny RG, Howanitz EP, Myerowith PD: A limited axillary thoracotomy as primary treatment for recurrent spontaneous pneumothorax. Chest 1993;103: 137-142.

4 Bertrand PC, Regnard JF, Spaggiari L, Levi JF, Magdeleinat P, Guibert $\mathrm{L}$, Levasseur P: Immediate and long-term results after surgical treatment of primary spontaneous pneumothorax by VATS. Ann Thorac Surg 1996;61:1641-1645.
5 Liu HP, Lin PJ, Hsieh MJ, Chang JP, Chang $\mathrm{CH}$ : Thoracoscopic surgery as a routine procedure of spontaneous pneumothorax: Results from 82 patients. Chest 1995;107: 559-562.

6 Nezu K, Kushibe K, Tojo T, Takahama M, Kitamura S: Thoracoscopic wedge resection of blebs under local anesthesia with sedation for treatment of a spontaneous pneumothorax. Chest 1997;111:230235. 
7 Passlick B, Born C, Haussinger K, Thetter O: Efficiency of video-assisted thoracic surgery for primary and secondary spontaneous pneumothorax. Ann Thorac Surg 1998; 65:324-327.

8 Kim KH, Kim HK, Han JY, Kim JT, Won YS, Choi SS: Transaxillary minithoracotomy versus video-assisted thoracic surgery for spontaneous pneumothorax. Ann Thorac Surg 1996;61:1510-1512.

9 Waller DA, Forty J, Morritt GN: Video-assisted thoracoscopic surgery versus thoracotomy for spontaneous pneumothorax. Ann Thorac Surg 1994;58:372-377.
10 Naunheim KS, Mack MJ, Hazelrigg SR, Ferguson MK, Ferson PF, Boley TM, Landreneau RJ: Safety and efficacy of video-assisted thoracic surgical techniques for the treatment of spontaneous pneumothorax. J Thorac Cardiovasc Surg 1995;109: 1198-1204.

11 Hazelrigg SR, Landreneau R, Mack M, Acuff T, Seifert PE, Auer JE, Magee M: Thoracoscopic stapled resection for spontaneous pneumothorax. J Thorac Cardiovasc Surg 1993; 105:389-393.

12 Mouroux J, Elkaim D, Padovani B, Myx A, Perrin C, Rotomondo C, Chavaillon JM, Blaire B, Richelme $\mathrm{H}$ : Video-assisted thoracoscopic treatment of spontaneous pneumothorax. Technique and results of one hundred cases. J Thorac Cardiovasc Surg 1996;112:385-391.
13 Inderbitzi RGC, Leiser A, Furrer M, Althaus U: Three years' experience in video-assisted thoracic surgery (VATS) for spontaneous pneumothorax. J Thorac Cardiovasc Surg 1994;107:1410-1415.

14 Cole FH Jr, Cole FH, Khandekar A, Maxwell JM, Pate JW, Walker WA: Video-assisted thoracic surgery: Primary therapy for spontaneous pneumothorax? Ann Thorac Surg 1995; 60:931-935

15 Goldstraw P: Endoscopy assisted microthoracotomy. Thorax 1992; 47:489. 